\title{
Is Metal Leakage from Aluminum Foil without Adverse Effects? A Study on Ants as Models
}

\section{Cammaerts $\mathrm{MC}^{*}$, and Cammaerts $\mathrm{R}^{2}$}

${ }^{1}$ Independent Researcher, Retired from the Biology of Organisms Department, University of Brussels, Belgium ${ }^{2}$ Independent Researcher, Retired from the Natural and Agricultural Environmental Studies Department (DEMNA) of the Walloon Region, Belgium

${ }^{*}$ Corresponding author: Cammaerts MC, Independent Researcher, Retired from the Department of Biology of Organisms, University of Brussels, 27, Square du Castel Fleuri, 1170 Bruxelles, Belgium, Tel: 32267349 69, E-mail: mccammaerts@gmail.com

Citation: Cammaerts MC, Cammaerts R (2018) Is Metal Leakage from Aluminum Foil without Adverse Effects? A Study on Ants as Models. J Nutr Health Sci 5(1): 103. doi: 10.15744/2393-9060.5.103

Received Date: December 07, 2017 Accepted Date: March 01, 2018 Published Date: March 07, 2018

\begin{abstract}
Aluminum is a metal largely present in many products used by humans (in vaccines, cosmetics, baby milk and packages for food among others). Such a presence is nowadays debated. Using ants as models, we showed that the presence of aluminum foil in their sugar water has effectively several adverse effects. It increased the ants' general activity, sugar water consumption, sinuosity of locomotion, and decreased their meat consumption, audacity, tactile perception, cognition, ability in escaping from an enclosure, and their ability in acquiring conditioning, affecting thus their short and middle term memory. It did not impact the individuals' social relationship. No habituation to these adverse effects occurred; no addiction developed. After consumption was stopped, the effects decreased slowly, linearly over time and vanished in 15 to 16 hours. Most of these effects discovered on ants agree with information on the effects of aluminum in mammals; a few ones have never been examined in mammals but might exist. However, people use aluminum foil without reserve. Since it effectively adversely impacts among others, the activity, locomotion and functioning of the nervous system, alternatives to the use of aluminum foil in food trade should be searched.
\end{abstract}

Keywords: Cognition; Locomotion; Memory; Movement; Sugar consumption

List of Abbreviations: Ang.deg: Angular degrees; Ang.deg./cm: Angular degrees per cm; mm/s: Millimeter per second; $\chi^{2}$ : Chi square; vs: Versus; $\mathrm{n}^{\circ}$ : Number; cm: Centimeter; mm: Millimeter; ml: Milliliter; $\mu$ l: Microliter; mg: Milligram; s: Second, min: Minute, h: Hours, t: Time, \%: Percentage

\section{Introduction}

Though aluminum $(\mathrm{Al})$ is the third most present element and the most abundant metal in the earth's crust, it has no recognized role for any known living organism and is normally not present in them [1,2]. When present in the body, Al is toxic and concerns about its use as a food additive were expressed as early as in 1911 [3]. It has not only a systemic toxicity [4], but also a recognized neurotoxicity [5] and is deemed to be linked to neurodegenerative pathologies such as Alzheimer's and Parkinson's diseases, even at low levels $[3,6,7]$. It is also associated with behavioral impairments such as autism $[8,9]$ and cognitive deficiencies $[4,10]$.

Despite the known health problems linked to its intake, $\mathrm{Al}$ is commonly used by humans in the form of $\mathrm{Al}$ hydroxide (as an adjuvant increasing the efficiency of vaccines) or as Al salts (in cosmetics, solar creams, deodorants, antiperspirants, pharmaceutical antacids, toothpastes, pastries, delicatessens and in soya-based formulae for babies). It may also be present in treated tap water $[11,12]$.

Moreover, one of the most usages of Al metal is for kitchen utensils, food and beverage packaging (cans and aluminum foil), and for trays and foil to cook food [13]. Al migration into aluminum-canned beverages increases during the storage [14] as well as with $\mathrm{pH}$ values of the drinks higher or lower than neutral [15]. Al migration is even higher in dented cans [16].

$\mathrm{Al}$ leaching while cooking in $\mathrm{Al}$ utensils increases with temperature, $\mathrm{pH}$ departure from neutral, salinity and time of exposure and significantly contributes to the daily intake of this metal through foods, particularly acidic ones [17-19]. According to Greger and co-authors [20], cooking beef, cabbage and eggs in $\mathrm{Al}$ pans leads to small though significantly more amount of $\mathrm{Al}$ in food 
than cooking in stainless steel pans. However, no significant release of Al occurred when ham, peas or potatoes were cooked in $\mathrm{Al}$ foil, except for mashed potatoes frozen in $\mathrm{Al}$ trays, the $\mathrm{Al}$ amount being then 4 times higher after cycles of freezing, thawing and refreezing. Nevertheless, according to another study [21], Al migration into halibut is 16 times higher when backing is made in $\mathrm{Al}$ foil than when it is made in roasting tubes. Concerning fish fillets, baked in $\mathrm{Al}$ foil, a meanly 2 to 6 fold $\mathrm{Al}$ increase was found, grilled in $\mathrm{Al}$ foil, a 5 to 11 fold increase occurred, and provided with onion and spices, a 11 to 68 fold was observed [22]. The amount of accumulated Al during the heating depended on the $\mathrm{pH}$-value of the food and on the duration of the cooking [22]. Baking meat in $\mathrm{Al}$ foil also increased the $\mathrm{Al}$ concentration by 2 to 5 times, the temperature and fat content significantly affecting the leakage [23]. However, most of these studies concluded that, due to the low amount of Al migrated into food, there was no risk for the health, since at the time of the experiments, this amount did not exceed the provisional tolerable weekly intake (PTWI) established at $7 \mathrm{mg} \mathrm{Al} / \mathrm{kg}$ bw [24].

A study with food-simulating solvents showed that Al migration from Al foil was 25-200 times higher into acidic liquids than into tap water, and that it depended on temperature and time [25]. Sodium chloride was also shown to enhance the dissolution of Al, while sugar, cholesterol and particularly proteins and amino acids were shown to reduce it [26]. Al leaching in beef cooked wrapped in $\mathrm{Al}$ foil was 60 times higher than in beef baked in a stainless steel pan, and became 70 times higher when spices and salt were added [27]. It was even recently demonstrated that Al leakage during boiling meat in Al foil with tomato juice, an alimentary acid and salt exceeded the PTWI of $1 \mathrm{mg} \mathrm{Al} / \mathrm{kg}$ bw [28] nowadays established by the World Health Organization [29] and the European Food Safety Authority [30]. The authors of this study recommended using Al foil for packing, but not for cooking [28].

A Belgian study showed that $\mathrm{Al}$ foil use in cooking contributes up to $64 \%$ of the total $\mathrm{Al}$ intake [31]. The authors suggested that avoiding the use of Al kitchenware could considerably reduce the risk of exceeding the aluminum PTWI in food.

In any way, humans are potentially exposed to ingest aluminum, what may impact their health. The present study deals with the putative effects of ingested $\mathrm{Al}$ metal by assessing the effects of water containing $\mathrm{Al}$ foil on ethological and physiological traits of ants used as biological models. Here below, we explain why ants can be used, which species we used and what we know on it, and which traits we intended to examined.

\section{Why Ants can Be Used as Models}

Physiological mechanisms, nervous system functioning, muscles functioning, genetics, some kinds of behavior, and nearly all the vital functions are similar for all animals, including humans [32,33]. It is the reason why most biological processes have been and are still studied on suitable animals used as models such as monkeys, rats, mice, parrots, as well as bees, fruit flies, crickets, cockroaches, mealworms and so on [34]. Invertebrates are preferentially used when it is possible due to their small size, their rapid development, and their easy maintenance, in large samples, in a laboratory [35]. Insects are often used, above all the hymenoptera such as bees [36]. Ants too can be used. They are highly evolved social insects. They have an evolved shutting of their mouth parts [37], as well as numerous glands producing efficient pheromones [38]. Their colonies present labor division, polyethism and social regulation [39,40]. They build complex nests, take care of their brood, differently mark the different parts of their habitat [39], and communicate thanks to informative chemical and tactile signals [40]. They navigate using memorized cues, adequately recruit nestmates, clean their nest and even manage cemeteries [39,40]. All these characters and abilities allow using them to examine the impacts of situations, products and environmental elements [41]. Moreover, ant colonies, containing large numbers of individuals, can be maintained during many years, at low cost, in ordinary rooms.

\section{Which Species We Used}

We have largely worked on ants of the genus Myrmica, making research on their ecology, eyes, angle of vision, vision, recruitment, navigation, learning [42], as well as on the ontogenesis of some of their abilities [43]. Studying the effect of manmade electromagnetism on their learning ability and their response to pheromones showed that they can be good biological models [44,45]. They were effectively good models when we examined, on them, the effects of alkaloids, nicotine, morphine and quinine, buprenorphine and methadone, fluoxetine, anafranil and efexor [41], paroxetine [46], carbamazepine [47], alprazolam, sweeteners, food complements and analgesics $[48,49]$. Each time, the effects presented by humans were observed, novel information was brought on them, and other effects of which humans may suffer were revealed. In the present work, we used M. sabuleti Meinert 1861 for studying the potential harmful impacts of aluminum.

\section{Which Traits We Examined}

We aimed to examine the effect of aluminum on 18 physiological and/or ethological traits, first on ants under normal diet, then on the same ants consuming aluminum, and thereafter, on 4 more traits only on ants consuming or having consumed aluminum. The 18 traits were: meat consumption, sugar water consumption, general activity, linear speed, angular speed, orientation towards an alarm signal, trail following, tendency in moving on an unknown apparatus, tactile ("pain”) perception, caring of brood, cognitive ability, aggressive behavior against nestmates, aggressiveness against aliens, ability in escaping from an enclosure, visual conditioning ability, visual memory, olfactory conditioning ability, and olfactory memory. The four other traits were: adaptation to the adverse effects of aluminum, habituation to its beneficial effects, dependence on its use, and the vanishing of its effects after its consumption was stopped. 
Adaptation exists when the adverse effects decrease over time. Habituation occurs when the beneficial effects decrease over time. Dependence appears when individuals consuming the product prefer food containing it than food free of it.

\section{Material and Methods}

Most of the material and the methods we here used are similar to those we previously employed. We thus only briefly relate them, inviting readers to find details in $[46,47,49]$ among others.

\section{Collection and Maintenance of Ants}

All the experiments were made on two colonies (A and B) of M. sabuleti collected in the Aise Valley (Ardenne, Belgium) in June 2016, and on a third colony, collected the same day on the same site, which furnished aliens and some controls. Every colony was kept in glass tubes half filled with water; the nest tubes of each colony were deposited in a tray $(34 \mathrm{~cm} \times 23 \mathrm{~cm} \times 4 \mathrm{~cm})$, as previously described, among others in $[44,45]$. The ants were fed with an aqueous solution of sugar given ad libidum in small cotton plugged tubes and with cut Tenebrio molitor larvae (Linnaeus, 1758) given three times per week. Laboratory parameters were optimum for the species $[46,47,49]$. The ants are here often named 'nestmates' as commonly do researchers on social insects.

\section{Liquid Containing Aluminum Given to the Ants}

A piece of aluminum foil $\left(3 \mathrm{~cm} \times 5 \mathrm{~cm}=15 \mathrm{~cm}^{2}\right)$ was cut in 10 parts (of $\left.1.5 \mathrm{~cm}^{2}\right)$ which were then set into $100 \mathrm{ml}$ of sugar water, then kept at $-15^{\circ} \mathrm{C}$ as a stock solution. The pieces of aluminum foil remained in this stock solution all along the entire experimental work. The tap water used had a $\mathrm{pH}$ of 7.75 [50]. The sugar water containing aluminum was delivered to the ants in their usual feeder tubes (which had a capacity of $5 \mathrm{ml}$ ). One to two pieces of aluminum foil were always present in these feeder tubes. It was checked each day if ants effectively drunk the provided solution, and they did. The cotton plug shutting the tubes was refreshed every 2-3 days, and the entire solution was renewed every 7 days.

\section{Sugar Water and Meat Consumption, General Activity}

The ants drinking the sugar water, eating the T. molitor larvae, and being active anywhere in their habitat were counted six times per day during six days, at the same times o' clock each time (Table 1, Daily counts), as done for previous works [49]. The mean of these daily counts were established (Table 1, Daily means) and the six daily means obtained for ants consuming sugar water containing aluminum were compared to those obtained for ants under normal diet using the non-parametric test of Wilcoxon [51]. The means of the daily means were also calculated (Table 1, Average of daily means).

\begin{tabular}{|c|c|c|c|c|c|c|}
\hline \multicolumn{4}{|c|}{ Sugar water diet } & \multicolumn{3}{|c|}{ Sugar water + aluminum diet } \\
\hline Days & Meat & Sugar water & Activity & Meat & Sugar water & Activity \\
\hline \multicolumn{7}{|c|}{ Daily counts } \\
\hline $\begin{array}{ll}\mathrm{I} & \mathrm{A} \\
& \mathrm{B}\end{array}$ & $\begin{array}{llllll}1 & 0 & 0 & 1 & 1 & 1 \\
0 & 0 & 1 & 1 & 1 & 1\end{array}$ & $\begin{array}{llllll}2 & 2 & 2 & 1 & 1 & 1 \\
0 & 1 & 0 & 1 & 1 & 1\end{array}$ & $\begin{array}{llllll}7 & 7 & 6 & 9 & 10 & 11 \\
15 & 16 & 14 & 16 & 17 & 17\end{array}$ & $\begin{array}{llllll}0 & 0 & 1 & 1 & 0 & 0 \\
1 & 1 & 1 & 0 & 0 & 1\end{array}$ & $\begin{array}{llllll}2 & 2 & 2 & 1 & 1 & 1 \\
0 & 0 & 1 & 1 & 0 & 0\end{array}$ & $\begin{array}{llllll}16 & 15 & 15 & 9 & 10 & 9 \\
9 & 10 & 11 & 13 & 14 & 13\end{array}$ \\
\hline $\begin{array}{ll}\text { II } & \mathrm{A} \\
& \mathrm{B}\end{array}$ & $\begin{array}{llllll}1 & 0 & 0 & 1 & 1 & 0 \\
1 & 1 & 1 & 1 & 1 & 0 \\
\end{array}$ & $\begin{array}{llllll}1 & 1 & 1 & 1 & 1 & 1 \\
1 & 1 & 0 & 1 & 1 & 2 \\
\end{array}$ & $\begin{array}{llllll}5 & 6 & 7 & 12 & 13 & 13 \\
12 & 13 & 12 & 15 & 14 & 16 \\
\end{array}$ & $\begin{array}{llllll}0 & 0 & 1 & 1 & 0 & 0 \\
1 & 0 & 0 & 1 & 1 & 1\end{array}$ & $\begin{array}{llllll}1 & 1 & 1 & 2 & 2 & 2 \\
1 & 0 & 0 & 0 & 0 & 1\end{array}$ & $\begin{array}{cccccc}9 & 10 & 10 & 12 & 13 & 12 \\
12 & 11 & 13 & 15 & 14 & 15\end{array}$ \\
\hline $\begin{array}{r}\text { III } \mathrm{A} \\
\mathrm{B}\end{array}$ & $\begin{array}{llllll}0 & 0 & 1 & 1 & 0 & 0 \\
1 & 0 & 0 & 0 & 0 & 1 \\
\end{array}$ & $\begin{array}{llllll}1 & 1 & 1 & 1 & 1 & 1 \\
3 & 3 & 2 & 2 & 2 & 2 \\
\end{array}$ & $\begin{array}{llllll}6 & 6 & 7 & 12 & 14 & 13 \\
8 & 8 & 7 & 18 & 16 & 17 \\
\end{array}$ & $\begin{array}{llllll}1 & 0 & 0 & 0 & 0 & 1 \\
0 & 0 & 1 & 0 & 0 & 0 \\
\end{array}$ & $\begin{array}{llllll}1 & 1 & 1 & 4 & 3 & 4 \\
1 & 2 & 2 & 1 & 1 & 1 \\
\end{array}$ & $\begin{array}{rrrrrr}10 & 9 & 10 & 14 & 15 & 14 \\
10 & 11 & 11 & 14 & 15 & 16\end{array}$ \\
\hline $\begin{array}{r}\text { IV A } \\
\text { B }\end{array}$ & $\begin{array}{llllll}0 & 0 & 1 & 1 & 0 & 0 \\
1 & 0 & 0 & 1 & 1 & 1 \\
\end{array}$ & $\begin{array}{llllll}1 & 0 & 0 & 1 & 1 & 1 \\
1 & 1 & 1 & 1 & 1 & 0 \\
\end{array}$ & $\begin{array}{cccccc}8 & 7 & 7 & 9 & 10 & 9 \\
10 & 10 & 11 & 18 & 17 & 18 \\
\end{array}$ & $\begin{array}{llllll}1 & 0 & 0 & 1 & 1 & 0 \\
0 & 0 & 1 & 0 & 0 & 0 \\
\end{array}$ & $\begin{array}{llllll}1 & 1 & 1 & 1 & 1 & 1 \\
0 & 0 & 1 & 1 & 1 & 1\end{array}$ & $\begin{array}{cccccc}9 & 10 & 9 & 14 & 15 & 14 \\
15 & 14 & 14 & 12 & 13 & 15 \\
\end{array}$ \\
\hline $\begin{array}{ll}\mathrm{V} & \mathrm{A} \\
& \mathrm{B}\end{array}$ & $\begin{array}{llllll}1 & 1 & 1 & 1 & 1 & 0 \\
1 & 1 & 1 & 1 & 1 & 1 \\
\end{array}$ & $\begin{array}{llllll}1 & 1 & 1 & 1 & 1 & 0 \\
0 & 0 & 1 & 1 & 1 & 1\end{array}$ & $\begin{array}{rrrrrr}13 & 10 & 11 & 16 & 12 & 14 \\
10 & 9 & 11 & 18 & 17 & 18 \\
\end{array}$ & $\begin{array}{llllll}1 & 1 & 1 & 1 & 0 & 0 \\
1 & 1 & 2 & 0 & 0 & 1 \\
\end{array}$ & $\begin{array}{llllll}1 & 1 & 1 & 1 & 1 & 0 \\
2 & 2 & 2 & 2 & 2 & 2 \\
\end{array}$ & $\begin{array}{lrrrrr}8 & 9 & 9 & 13 & 14 & 15 \\
12 & 13 & 13 & 22 & 20 & 21 \\
\end{array}$ \\
\hline $\begin{array}{r}\text { VI } \mathrm{A} \\
\mathrm{B}\end{array}$ & $\begin{array}{llllll}1 & 0 & 0 & 1 & 1 & 0 \\
0 & 0 & 1 & 1 & 1 & 1\end{array}$ & $\begin{array}{llllll}2 & 2 & 2 & 1 & 0 & 1 \\
1 & 1 & 1 & 1 & 0 & 0 \\
\end{array}$ & $\begin{array}{llllll}10 & 11 & 12 & 12 & 14 & 13 \\
10 & 10 & 11 & 18 & 19 & 18\end{array}$ & $\begin{array}{llllll}1 & 1 & 0 & 1 & 1 & 0 \\
0 & 0 & 0 & 0 & 0 & 1\end{array}$ & $\begin{array}{llllll}1 & 1 & 1 & 3 & 4 & 3 \\
5 & 5 & 5 & 1 & 1 & 1\end{array}$ & $\begin{array}{cccccc}9 & 10 & 9 & 20 & 19 & 20 \\
15 & 15 & 14 & 22 & 24 & 23\end{array}$ \\
\hline \multicolumn{7}{|c|}{ Daily means } \\
\hline I & 0.66 & 1.08 & 12.08 & 0.50 & 1.00 & 12.00 \\
\hline II & 0.66 & 1.00 & 11.33 & 0.50 & 0.92 & 12.17 \\
\hline III & 0.33 & 1.67 & 11.08 & 0.25 & 1.83 & 12.42 \\
\hline IV & 0.50 & 0.75 & 11.16 & 0.33 & 0.83 & 12.83 \\
\hline $\mathrm{V}$ & 0.92 & 0.75 & 13.25 & 0.75 & 1.42 & 14.08 \\
\hline VI & 0.58 & 1.00 & 13.17 & 0.42 & 2.58 & 16.67 \\
\hline \multicolumn{7}{|c|}{ Average of daily means } \\
\hline & 0.61 & 1.04 & 10.35 & 0.46 & 1.43 & 13.36 \\
\hline
\end{tabular}

Ants of colonies A and B eating meat, drinking sugar water, and being active were counted 6 times per day, during 6 days. The daily means were calculated, as well as the average of these daily means. Experimental details and statistics are given in the text. Aluminum (given in sugar water) somewhat decreased meat consumption, increased sugar water consumption, and increased activity

Table 1: Effect of aluminum on ants' food consumption, and general activity 


\section{Speeds of Locomotion and Orientation Ability}

As previously $[42,43,45]$, the experiments were made on ants freely moving in their tray. The linear and angular speeds were quantified giving no stimulus to the ants; the orientation to an alarm signal was quantified presenting them with a nestmate tied to a piece of white paper (Figure 1A). Such a tied worker emits its alarm pheromone produced by its mandible glands. As previously [49], for each variable, the trajectory of 20 ants of each colony ( $n=20$ ants $\times 2$ colonies $=40$ trajectories) was recorded on glass and then copied on an appropriate substrate which remained affixed to a PC monitor screen due to its static electricity charge. As in previous works $[46,47,49]$, the recorded trajectories were analyzed using specifically designed software [52]. The linear speed (in $\mathrm{mm} / \mathrm{s}$ ) is the length of a trajectory divided by the time spent for travelling it. The angular speed (in ang. deg./ $/ \mathrm{cm}$ ) is the sum of the angles, measured at several successive points of the trajectory, between the segment 'point $\mathrm{i}$ to point $\mathrm{i}-1$ ' and the following segment 'point i to point i+1', divided by the length of the trajectory. The orientation to a given point (in ang. deg.) is the sum of the angles, measured at several successive points of the trajectory, between the segment 'point i of the trajectory-given point' and each segment 'point i-point i+1', divided by the number of measured angles. If the obtained value is lower than $90^{\circ}$, the animal has a tendency to orient itself towards the point; if it is larger than $90^{\circ}$, the animal has a tendency to avoid the point. Each distribution of 40 values was characterized by its median and quartiles (Table 2, lines 1,2,3) and the distributions obtained for ants consuming aluminum were compared to those obtained for ants under normal diet, using the non-parametric $\chi^{2}$ test [51].

\begin{tabular}{|c|c|c|}
\hline Traits & Sugar water diet & Sugar water + aluminum diet \\
\hline Linear speed (mm/s) & $14.1(11.7-15.4)$ & $13.7(12.1-14.8)$ \\
\hline Angular speed (ang.deg./cm) & $126(108-147)$ & $148(132-158)$ \\
\hline Orientation (ang. deg.) & $38.3(29.2-53.4)$ & $59.9(48.1-67.7)$ \\
\hline Trail following ( ${ }^{\circ}{ }^{\text {arcs})}$ & $12.5(8.0-18.0)$ & $5.0(3.0-9.0)$ \\
\hline Audacity ( ${ }^{\circ}$ ants) & $1.25[0-2]$ & $0.90[0-2]$ \\
\hline \multicolumn{2}{|c|}{ Tactile (pain) perception } \\
\hline linear speed (mm/s) & $4.7(4.4-6.2)$ & $8.4(7.8-9.3)$ \\
\hline angular speed (ang.deg./cm) & $257(220-311)$ & $192(169-205)$ \\
\hline
\end{tabular}

Experimental details and statistics are given in the text. Aluminum increased the ants' sinuosity of movement, decreased their orientation ability, their trail following, their audacity, and largely their tactile perception

Table 2: Effect of aluminum on six physiological and/or ethological traits

\section{Trail Following Behavior}

The method is described in many previous works $[46,47,49]$. The trail pheromone of Myrmica ants is produced by the workers' poison gland. A solution of 10 of these glands in $500 \mu \mathrm{l}$ of hexane was made and set for $15 \mathrm{~min}$ at $-25^{\circ} \mathrm{C}$. To make an experiment, $50 \mu \mathrm{l}$ of the solution was deposited, thanks to a metallic normograph pen, on a circle $(\mathrm{R}=5 \mathrm{~cm})$ pencil drawn on white paper and divided into 10 angular degrees arcs. One minute later, this artificial trail was deposited in the ants' tray, and the response of 20 ants of each colony to that trail was assessed by the number of arcs of 10 angular degrees the ants walked along the trail without departing from it (Figure 1B). The distribution of the 40 values was characterized by its median and quartiles (Table 2, line 4 ), and the distribution obtained for ants consuming aluminum was compared to that obtained for ants under normal diet using the non-parametric $\chi^{2}$ test.

\section{Audacity}

The method has already been used in several previous works $[46,47,49]$. A tower standing on a platform, both being made of strong white paper (Steinbach ${ }^{\circledR}$, height $=4 \mathrm{~cm}$; diameter $=1.5 \mathrm{~cm}$ ), was set in the ants' tray, and the ants present at any place of this unknown apparatus were counted 12 times over $12 \mathrm{~min}$ (Figure 1C). The mean and the extremes of the obtained values were established (Table 2). The values obtained for the two colonies as well as those obtained during each successive time period of two minutes were pulled and the results for ants under aluminum and normal diets were compared using the Wilcoxon test.
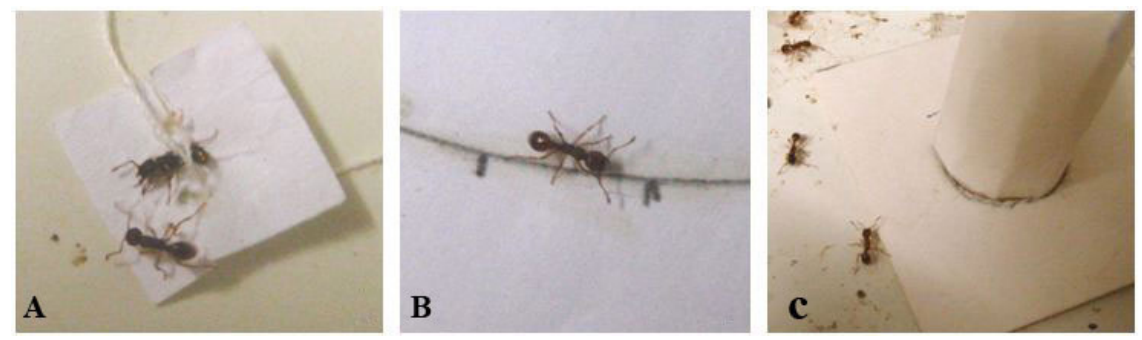

Figure 1: Some views of the experiments. A: an ant under normal diet having reached a tied nestmate which emits its alarm pheromone. B: an ant under aluminum diet following for a time a circular trail. C: three ants under aluminum diet not inclined in coming onto an unknown and risky apparatus 


\section{Tactile ('Pain') Perception}

An ingested product may adversely impact the central and the sensitive nervous system. This is why we assessed the ants' locomotion on a rough substrate (and later, on several cognitive abilities), doing so after the ants consumed aluminum for 5 days. Ants correctly perceiving the uncomfortable character of the substrate walk with difficulties, slowly, sinuously, while ants poorly perceiving such a character walk more confidently, more quickly and less sinuously. As previously [46,47,49], a folded piece (length: $3 \mathrm{~cm}$, width: $2+7+2=11 \mathrm{~cm}$ ) of rough emery $\mathrm{n}^{\circ} 280$ paper was tied to the bottom and the borders of a tray $(15 \mathrm{~cm} x 7 \mathrm{~cm} \mathrm{x}$ $4.5 \mathrm{~cm}$ ), the tray becoming so divided into a small zone $3 \mathrm{~cm}$ long, a zone $3 \mathrm{~cm}$ long where ants' moving was difficult (Figure 1D), and a $9 \mathrm{~cm}$ long smooth zone. Each colony had its own apparatus $(3+3+9 \mathrm{~cm}=15 \mathrm{~cm}$, the length of the tray). For each of them, 12 ants were deposited, at a time, in the small zone. When moving away from that zone, the ants walked for a time on the rough paper. During that time, their speed of locomotion and their sinuosity were assessed $(\mathrm{n}=12$ trajectories $\times 2$ colonies $=24$; Table 2 , line 6). The values obtained for ants consuming aluminum were compared to those obtained for ants under normal diet using the non-parametric $\chi^{2}$ test.

\section{Brood Caring}

Ants of colonies A and B set their brood far from their nest entrance, at an inaccessible place inside the nest. The usual protocol allowing studying the ants' care of brood could no longer be used (removing larvae from the nest and assessing the ants' relocation of them inside the nest) and a novel one was set up. Before the ants consumed aluminum, then after they had consumed that product for 7 days, we observed the brood of each colony, together with the ants located on and in the vicinity of the brood (Figure 1E). During each observation, we recorded over 15 minutes, at the end of each minute, the number of ants present on and very near the brood (='p'), as well as the number of ants interacting with the brood (='i'), i.e., licking, moving, relocating a larva, regurgitating food. For each kind of diet, the 15 'p' numbers as well as the 15 'i' numbers recorded for each colony were added and the mean proportion of ' $\mathrm{p} / \mathrm{i}$ ' was calculated (Table 3, line 1). The numbers ' $\mathrm{p}$ ' and ' $\mathrm{i}$ ' obtained for ants under aluminum diet were compared to the corresponding numbers previously obtained for ants under normal diet using the non-parametric $\chi^{2}$ test for $2 \times 2$ contingency tables [51].
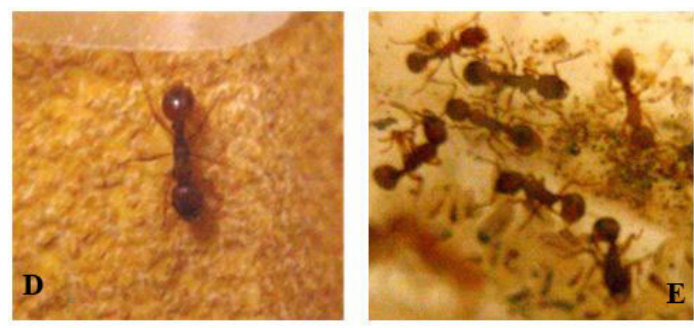

Figure 1: Some views of the experiments. D: an ant under aluminum diet moving frankly on a rough, uncomfortable substrate. E: ants under aluminum diet taking care of their brood inside the nest.

\begin{tabular}{|c|c|c|c|c|c|c|}
\hline Traits & \multicolumn{3}{|c|}{ Normal diet } & \multicolumn{3}{|c|}{ Diet with aluminum } \\
\hline \multirow{2}{*}{ Brood caring } & $\mathrm{p}$ & i & $\mathrm{i} / \mathrm{p}$ & $\mathrm{p}$ & $\mathrm{i}$ & $\mathrm{i} / \mathrm{p}$ \\
\hline & 143 & 76 & 0.53 & 158 & 89 & 0.56 \\
\hline \multirow{8}{*}{$\begin{array}{l}\text { Cognition: ants in front of and } \\
\text { beyond twists and turns in the } \\
\text { course of } 12 \mathrm{~min}\end{array}$} & $\mathrm{t}$ & $\mathrm{n}^{\circ}$ in front & $\mathrm{n}^{\circ}$ beyond & $\mathrm{t}$ & $\mathrm{n}^{\circ}$ in front & $\mathrm{n}^{\circ}$ beyond \\
\hline & $30 s$ & 23 & 0 & $30 \mathrm{~s}$ & 27 & 0 \\
\hline & 2 & 18 & 0 & 2 & 23 & 2 \\
\hline & 4 & 17 & 1 & 4 & 19 & 2 \\
\hline & 6 & 13 & 1 & 6 & 19 & 3 \\
\hline & 8 & 11 & 3 & 8 & 17 & 3 \\
\hline & 10 & 10 & 4 & 10 & 16 & 3 \\
\hline & 12 & 10 & 6 & 12 & 16 & 4 \\
\hline Aggressiveness against nestmates & $\begin{array}{c}\text { levels } \\
\mathrm{n}^{\circ}\end{array}$ & $\begin{array}{cccc}0 & 1 & 2 & 3 \\
65 & 42 & 11 & 0\end{array}$ & $\begin{array}{ll}4 & \text { var 'a' } \\
0 & 0.10\end{array}$ & $\begin{array}{c}\text { levels } \\
\mathrm{n}^{\circ}\end{array}$ & $\begin{array}{llll}0 & 1 & 2 & 3 \\
53 & 40 & 15 & 0\end{array}$ & $\begin{array}{ll}4 & \text { var 'a' } \\
0 & 0.16\end{array}$ \\
\hline Aggressiveness against aliens & $\begin{array}{l}\text { levels } \\
n^{\circ}\end{array}$ & $\begin{array}{cccc}0 & 1 & 2 & 3 \\
5 & 28 & 53 & 56\end{array}$ & $\begin{array}{c}4 \text { var 'a' } \\
394.50\end{array}$ & $\begin{array}{l}\text { levels } \\
\mathrm{n}^{\circ}\end{array}$ & $\begin{array}{clll}0 & 1 & 2 & 3 \\
17 & 21 & 52 & 62\end{array}$ & $\begin{array}{l}4 \quad \text { var 'a' } \\
39 \quad 3.90\end{array}$ \\
\hline $\begin{array}{l}\text { Escaping from an enclosure: ants } \\
\text { in and out of the enclosure in } \\
\text { the course of } 12 \mathrm{~min}\end{array}$ & $\begin{array}{l}\mathrm{t}: \\
\mathrm{n}^{\circ} \text { in } \\
\mathrm{n}^{\circ} \text { out }\end{array}$ & $\begin{array}{cccc}30 s & 2 & 4 & 6 \\
12 & 10 & 8 & 7 \\
0 & 2 & 4 & 5 \\
\text { ariable }= & 11 /\end{array}$ & $\begin{array}{rrr}8 & 10 & 12 \\
5 & 3 & 1 \\
7 & 9 & 11 \\
12 & =0.91\end{array}$ & $\begin{array}{l}\mathrm{t}: \\
\mathrm{n}^{\circ} \text { in: } \\
\mathrm{n}^{\circ} \text { out }\end{array}$ & $\begin{array}{cccc}30 s & 2 & 4 & 6 \\
12 & 12 & 12 & 12 \\
0 & 0 & 0 & 0 \\
\text { variable }= & 2 / 12\end{array}$ & $\begin{array}{ccc}8 & 10 & 12 \\
12 & 11 & 10 \\
0 & 1 & 2 \\
= & 0.17\end{array}$ \\
\hline
\end{tabular}

Experimental details and statistics can be found in the text. Aluminum did not impact the ants' brood caring and their behavior in front of nestmates and aliens, but largely impacted their cognition and ability in escaping from an enclosure. p: number of ants present on the brood; i: number of ants interacting with the brood; aggressiveness levels: 0 : doing nothing, 1: antennal contact, 2 : mandibles opening, 3: gripping, 4: stinging; var $\mathrm{a}=\mathrm{n}^{\circ}(2+3+4) / \mathrm{n}^{\circ}(0+1)$

Table 3: Effects of aluminum on five physiological and/or ethological traits 


\section{Cognition}

This protocol was set up when studying the effects of nicotine [53]. Two folded pieces of white strong paper (Steinbach ${ }^{\circledR}, 12$ $\mathrm{cm} \times 4.5 \mathrm{~cm})$ were inserted in a tray $(15 \mathrm{~cm} \times 7 \mathrm{~cm} \times 4.5 \mathrm{~cm})$ for creating a path with twists and turns between an initial small loggia and a large one. Each colony had its own apparatus. For each of them, 15 ants were set all together in the initial loggia, and just after, the ants present in this initial loggia and in the large one were counted after 30s, 2,4,6,8,10 and 12 min. The numbers obtained for the two colonies were added (Table 3, line 2), and the sums obtained for ants consuming aluminum were compared to those obtained for ants under normal diet using the non-parametric Wilcoxon test.

\section{Aggressive Behavior against Nestmates and Aliens}

This treat was assessed as previously $[46,47,49]$. Five dyadic encounters with a nestmate and with an alien were realized for each colony. Each encountering was conducted in a small cylindrical cup (diameter $=2 \mathrm{~cm}$, height $=1.6 \mathrm{~cm}$ ), the borders of which being slightly covered with talc. Each time $(5 \times 2=10$ encounters with nestmates, $5 \times 2=10$ encounters with aliens), one ant of colony A or $\mathrm{B}$ was observed during $5 \mathrm{~min}$ and its encounter with the opponent was characterized, as previously, by the number of times it did nothing (level 0 of aggressiveness), touched the other ant with its antennae (level 1), opened its mandibles (level 2), gripped and/ or pulled the other ant (level 3), tried to sting or stung the other ant (level 4) (Figure 1F, G). The numbers recorded for the two colonies were added (Table 3, lines 3,4), and the results obtained for ants under aluminum diet were compared to those obtained for ants under normal diet using the non-parametric $\chi^{2}$ test. As in previous works [46], the ants' aggressiveness was also quantified by 'a', equaling the number of recorded aggressiveness levels $2+3+4$ divided by the number of recorded levels $0+1$.

\section{Escaping From an Enclosure}

As in previous works $[46,47,49]$, for each colony, six ants were enclosed in a reversed polyacetate glass $(\mathrm{h}=8 \mathrm{~cm}$, bottom diameter $=7$ $\mathrm{cm}$, ceiling diameter $=5 \mathrm{~cm}$ ) set in the ants' foraging area. The rim of the bottom of the glass was provided with a small notch $(3$ $\mathrm{mm}$ height, $2 \mathrm{~mm}$ broad) for giving to the ants the opportunity of escaping from the enclosure (Figure $1 \mathrm{H}$, I. To quantify such ability, the ants still under the glass and those escaped after $30 \mathrm{~s}, 2,4,6,8,10$ and $12 \mathrm{~min}$ were counted. The results obtained for the two colonies were added (Table 3, line 5), and the sums obtained for ants consuming aluminum were compared to those obtained for ants under normal diet using the non-parametric Wilcoxon test. As previously [42,43,45], we also evaluated the ants' ability in escaping by the variable " $\mathrm{n}{ }^{\circ}$ of ants escaped after $12 \mathrm{~min} / 12$ ".
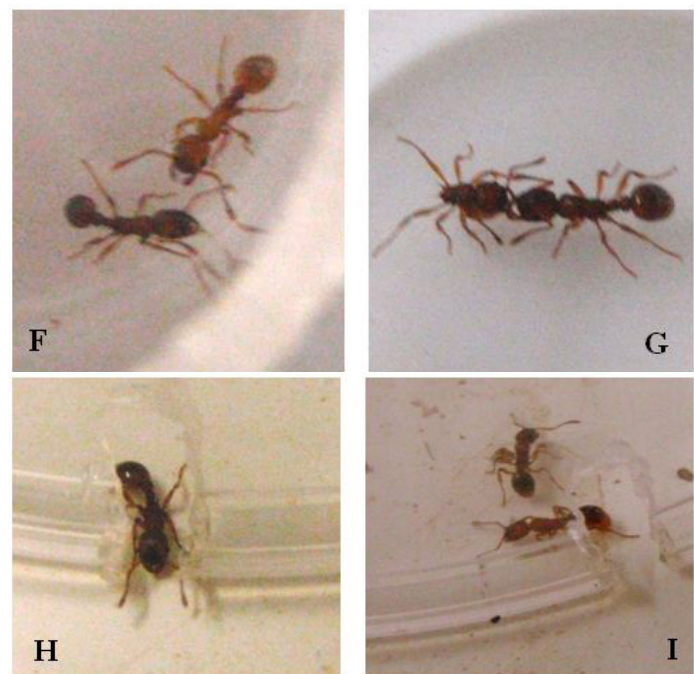

Figure 1: Some views of the experiments. F: two nestmates under aluminum diet staying side by side with no aggressiveness. G: an ant under aluminum diet stinging an alien. $\mathbf{H}$ : an ant under normal diet escaping from an enclosure. I: ants under aluminum diet unable to escape from an enclosure

\section{Visual and Olfactory Conditioning and Memory}

The protocol of these experiments have been set up many years ago and used several times, among others in [46,47,49]. Here, we used it again for studying the effect of aluminum on learning and memorizing capabilities, experimenting on colonies A and $\mathrm{B}$ after they had consumed aluminum for 7 days, and using control results previously obtained on colony C, never provided with that compound, while studying the effects of statins [54]. At a given time, a yellow hollow cube under which the ants could go was set above the entrance of the sugar water tube, the ants undergoing so visual operant conditioning. One week later, after the end of that visual conditioning experiment, pieces of basilica were deposited all around the entrance of the sugar water tube, the ants undergoing then olfactory operant conditioning. Tests were performed over time, while ants were expected to acquire conditioning and after removal of the cue, while they were expected to lose it. The ants were individually tested in a Y-apparatus constructed of strong white paper, and set in a small tray $(30 \mathrm{~cm} \times 15 \mathrm{~cm} \times 4 \mathrm{~cm})$, as explained in previous studies [same references 
as above]. The Y-apparatus was provided with a yellow hollow cube or pieces of basilica in one branch. Half of the tests were conducted with the cue in the left branch and the other half with the cue in the right branch. Moving into the branch containing the cue was considered as giving the correct response (Figure 1J, K). For each test, 10 ants of each colony were tested, the numbers of ants under aluminum diet being thus 10 ants $\times 2$ colonies $=20$ ants, and of ants under normal diet, $n=10$. The percentage of correct responses was established for each test (Table 4). The results obtained for ants under one and the other diet were compared thanks to the non-parametric Wilcoxon test.
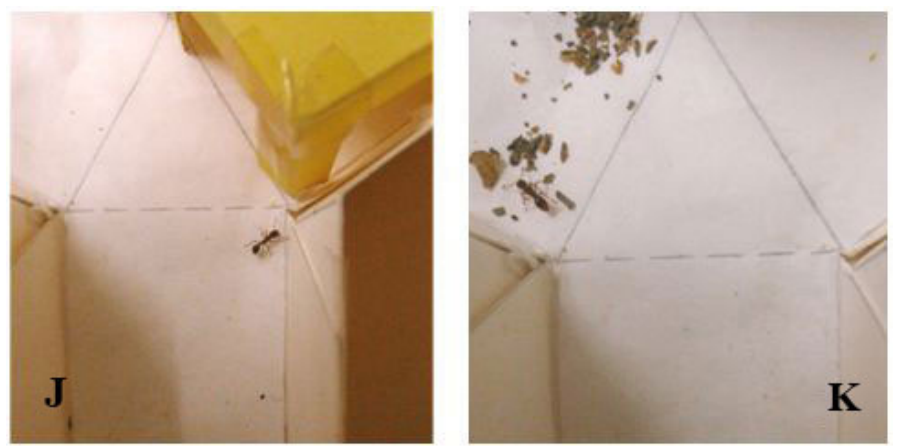

Figure 1: Some views of the experiments. J: an ant under aluminum diet, trained to a hollow yellow cube, hesitating to give to correct response when tested in a Y apparatus provided with that cue. K: an ant under aluminum diet, trained to basilica, giving the correct response when tested in a Y apparatus provided with that cue

\begin{tabular}{|c|c|c|c|c|c|}
\hline \multirow{2}{*}{ time (h) } & \multicolumn{2}{|c|}{ Sugar water diet ${ }^{*}$} & \multicolumn{3}{|c|}{ Sugar water + aluminum diet } \\
\hline & colony $\mathrm{C}$ & $\%$ & colony A & colony B & $\%$ \\
\hline \multicolumn{6}{|c|}{ Visual conditioning } \\
\hline 7 & 7 & 70 & 4 & 6 & 50 \\
\hline 24 & 8 & 80 & 4 & 6 & 50 \\
\hline 31 & 8 & 80 & 3 & 5 & 40 \\
\hline 48 & 8 & 80 & 5 & 6 & 55 \\
\hline 55 & 8 & 80 & 3 & 6 & 45 \\
\hline 72 & 8 & 80 & 4 & 6 & 50 \\
\hline \multicolumn{6}{|c|}{ Visual memory } \\
\hline 7 & 8 & 80 & \multirow{6}{*}{\multicolumn{3}{|c|}{$\begin{array}{l}\text { no short and middle term } \\
\text { memory }\end{array}$}} \\
\hline 24 & 7 & 70 & & & \\
\hline 31 & 8 & 80 & & & \\
\hline 48 & 7 & 70 & & & \\
\hline 55 & 7 & 70 & & & \\
\hline 72 & 7 & 70 & & & \\
\hline \multicolumn{6}{|c|}{ Olfactory conditioning } \\
\hline 7 & 7 & 70 & 3 & 5 & 40 \\
\hline 24 & 8 & 80 & 5 & 4 & 45 \\
\hline 31 & 8 & 80 & 5 & 4 & 45 \\
\hline 48 & 9 & 90 & 4 & 7 & 55 \\
\hline 55 & 9 & 90 & 5 & 3 & 40 \\
\hline 72 & 9 & 90 & 5 & 4 & 45 \\
\hline \multicolumn{6}{|c|}{ Olfactory memory } \\
\hline 7 & 9 & 90 & \multirow{6}{*}{\multicolumn{3}{|c|}{$\begin{array}{l}\text { no short and middle term } \\
\text { memory }\end{array}$}} \\
\hline 24 & 8 & 80 & & & \\
\hline 31 & 8 & 80 & & & \\
\hline 48 & 7 & 70 & & & \\
\hline 55 & 8 & 80 & & & \\
\hline 72 & 8 & 80 & & & \\
\hline
\end{tabular}

Ants were trained to a visual, then an olfactory cue, and tested over time in a Y-apparatus provided with the cue in one of its branches. Details and statistics are given in the text. Aluminum drastically impacted the ants' ability in acquiring conditioning, and thus their short and middle term visual and olfactory memory. * : control results previously obtained in [54]

Table 4: Impact of aluminum on ants' conditioning ability and memory 


\section{Adaptation to Aluminum Consumption}

After the ants lived under a diet with aluminum during 10 days, their angular speed was again assessed (Table 5, line 1) in the manner it had been before consuming the food complement and after they had consumed it for one day, in order to examine if ants went on walking sinuously or if they became adapted to the effect of that compound on their locomotion. The distribution of values obtained after 10 days of aluminum consumption was compared to the control one and to that obtained after one day of aluminum consumption using the non-parametric $\chi^{2}$ test.

\begin{tabular}{|c|c|c|c|}
\hline Traits & $\begin{array}{c}\text { Under normal diet } \\
\text { (control) }\end{array}$ & $\begin{array}{c}\text { Under AL diet } \\
\text { since one or 5 days }\end{array}$ & $\begin{array}{c}\text { Under AL diet } \\
\text { since 10 or 11 days }\end{array}$ \\
\hline $\begin{array}{c}\text { Angular speed on a } \\
\text { normal substrate }\end{array}$ & $126(108-147)$ & $148(132-158)$ & $159(139-191)$ \\
\hline $\begin{array}{c}\text { Linear speed } \\
\text { Angular speed } \\
\text { on a rough substrate }\end{array}$ & $\begin{array}{c}4.7(4.4-6.2) \\
257(220-311)\end{array}$ & $\begin{array}{c}8.4(7.8-9.3) \\
192(169-205)\end{array}$ & $\begin{array}{c}9.6(8.8-10.8) \\
163(134-180)\end{array}$ \\
\hline
\end{tabular}

Angular speed in ang.deg./cm; linear speed in $\mathrm{mm} / \mathrm{s}$; normal diet=sugar water diet; $\mathrm{Al}$ diet=sugar water+aluminum diet. These traits, i.e., sinuosity and tactile perception, initially impacted by aluminum (see Table 2), were still impacted after 10 or 11 days of $\mathrm{Al}$ ingestion. Ants developed thus no adaptation to the adverse effects of aluminum

Table 5: Adaptation to the impact of aluminum on sinuosity of movement and on tactile perception (i.e., locomotion on a rough substrate)

After the ants consumed aluminum since 11 days, their locomotion on a rough substrate (so, their tactile and pain perception, impacted by that compound) was again quantified (Table 5 , line 2 ) in the manner it had been before the ants consumed aluminum and after they had consumed it for 5 days, in order to know if ants adapted themselves to the impact of aluminum on their perception. The numerical results obtained after 11 days of consumption were compared to the control ones and to those obtained after 5 days of consumption using the non-parametric Wilcoxon test.

\section{Habituation to Aluminum Consumption}

This trait was not examined, a decision taken after having examined all the here above potential effects of aluminum.

\section{Dependence on Aluminum Consumption}

After the ants lived under an aluminum diet during 12 days, we conducted an experiment in order to reveal if they became dependent on that product. The protocol of this experiment was identical to that used for examining potential ants' addiction to different substances $[46,47,49]$. For colony A and for colony B, 15 ants were removed and set in a small tray $(15 \mathrm{~cm} \times 7 \mathrm{~cm} \times 5 \mathrm{~cm})$ in which two tubes $(\mathrm{h}=2.5 \mathrm{~cm}$, diam. $=0.5 \mathrm{~cm})$ had been deposited, one containing sugar water, the other containing a sugar solution of aluminum i.e., the solution used throughout the hole study (Figure 1L). In one tray, the tube containing aluminum was deposited on the right, and in the other tray, it was deposited on the left. After that, the ants seen drinking each liquid were counted 15 times over $15 \mathrm{~min}$. The two sums of these two different counts were compared to those which should have been obtained if ants randomly went drinking each kind of provided liquid, using the non-parametric goodness of fit $\chi^{2}$ test [51]. On the basis of these two sums, we also established the proportion of ants which have chosen each kind of liquid.

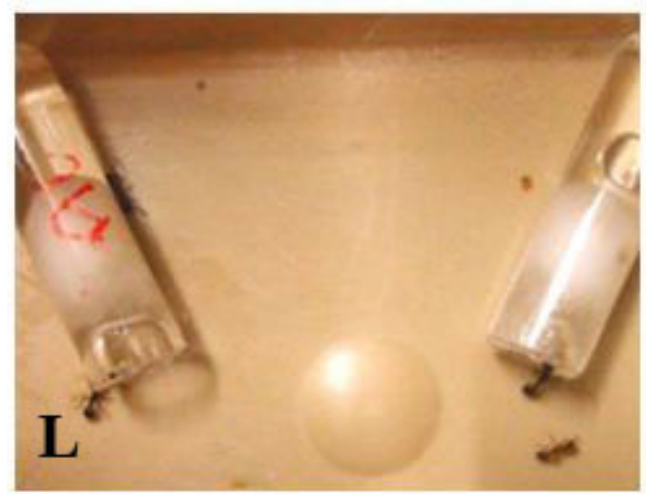

Figure 1: Some views of the experiments. L: ants under aluminum diet not preferentially choosing sugar water containing this metal (tube with the red label 'al') when confronted to it and to aluminum-free sugar water (tube with no label)

\section{Loss of the Effects of Aluminum after Its Consumption was stopped}

The protocol of such a study is detailed in previous works, for instance in [49]. A fresh solution of aluminum was provided to 
the ants 12 hours before the start of the present experiment (and a first assessment was made at $t=0$ ) which began just when that solution of aluminum was replaced by an aqueous solution of sugar, free of the compound. Since that weaning time, the ants' angular speed (=sinuosity) was assessed just like it had been before the ants consumed the food complement, after they had consumed it for one day and after they had consumed it for 10 days, except that 20 instead of 40 ant's trajectories were recorded for being able to make the assessments in the course of the experimentation. These assessments were performed after several time periods. The obtained numerical results were compared to those obtained at $t=0$ (see here above) and to the control ones, taking these two latter values as control groups in a non-parametric Kruskal-Wallis ANOVA for multiple comparisons [51], using Statistica ${ }^{\circledR}$ v.10 software. The non-parametric $\chi^{2}$ test was also used for comparing some distributions. All tests were two-tailed. The results of the present experiment are given in Table 6, and graphically presented in Figure 2 . The experiment ended when the ants' angular speed became similar to that presented under normal diet.

\begin{tabular}{|c|c|c|c|c|c|}
\hline \multirow{2}{*}{$\begin{array}{r}\text { Experiments } \\
\text { time (h) }\end{array}$} & \multirow{2}{*}{$\begin{array}{l}\text { Angular speed } \\
\text { (ang.deg./cm) }\end{array}$} & \multicolumn{2}{|c|}{ Statistics vs normal diet } & \multicolumn{2}{|c|}{ Statistics vs $\mathbf{t}=\mathbf{0}$} \\
\hline & & $\mathrm{K}-\mathrm{W}$ test & $\chi^{2}$ test & $\mathrm{K}-\mathrm{W}$ test & $\chi^{2}$ test \\
\hline $\begin{array}{c}\text { Normal diet } \\
1 \text { day Al diet } \\
10 \text { days Al diet }\end{array}$ & $\begin{array}{l}126(108-147) \\
148(132-158) \\
159(139-191)\end{array}$ & & & & \\
\hline $0 \mathrm{~h}$ : weaning & $169(149-186)$ & & & & \\
\hline then since $2 \mathrm{~h}$ & $167(147-194)$ & $\mathrm{P}=0.0002$ & $0.001<\mathrm{P}<0.01$ & $\mathrm{P}=0.051$ & $\mathrm{P}=0.80$ \\
\hline $4 \mathrm{~h}$ & $165(150-177)$ & $\mathrm{P}=0.0000$ & $\mathrm{P}<0.001$ & $\mathrm{P}=0.045$ & $\mathrm{P}=1$ \\
\hline $6 \mathrm{~h}$ & $158(147-177)$ & $\mathrm{P}=0.0003$ & $0.001<\mathrm{P}<0.01$ & $\mathrm{P}=0.049$ & $\mathrm{P}=0.90$ \\
\hline $8 \mathrm{~h}$ & $153(131-170)$ & $\mathrm{P}=0.01$ & $0.05<\mathrm{P}<0.10$ & $\mathrm{P}=0.017$ & $0.50<\mathrm{P}<0.70$ \\
\hline $10 \mathrm{~h}$ & $146(117-162)$ & $\mathrm{P}=0.11$ & $P=0.30$ & $\mathrm{P}=0.104$ & $0.20<\mathrm{P}<0.30$ \\
\hline $12 \mathrm{~h}$ & $140(118-158)$ & $\mathrm{P}=0.11$ & $P=0.80$ & $\mathrm{P}=0.039$ & $0.05<\mathrm{P}<0.10$ \\
\hline $14 \mathrm{~h}$ & $133(116-165)$ & $\mathrm{P}=0.11$ & $0.30<\mathrm{P}<0.50$ & $\mathrm{P}=0.035$ & $0.10<\mathrm{P}<0.20$ \\
\hline $16 \mathrm{~h}$ & $124(102-146)$ & $\mathrm{P}=0.11$ & $0.70<\mathrm{P}<0.80$ & $\mathrm{P}=0.0003$ & $\mathrm{P} \sim 0.001$ \\
\hline
\end{tabular}

After having again assessed the ants' sinuosity while under aluminum diet (note that the effect of aluminum on that trait increased over its consumption time), weaning began when the ants' solution of aluminum was replaced by pure sugar water. Since that time $t=0$, the ants' sinuosity was assessed until it equaled again the control one. The effect of aluminum decreased slowly, linearly over time, and vanished in 15 to 16 hours. The ants' sinuosity in function of weaning time is plotted in Figure 2. Details are given in the text. Columns 3 and 4: statistical comparison with control values; columns 5 and 6: statistical comparison with values at $\mathrm{t}=0$; $\mathrm{K}-\mathrm{W}$ test=non-parametric Kruskall-Wallis ANOVA; $\chi^{2}$ test $=$ non-parametric $\chi^{2}$ test (bilateral tests)

Table 6: Loss of the impact of aluminum on the ants' sinuosity of movement after its consumption was stopped

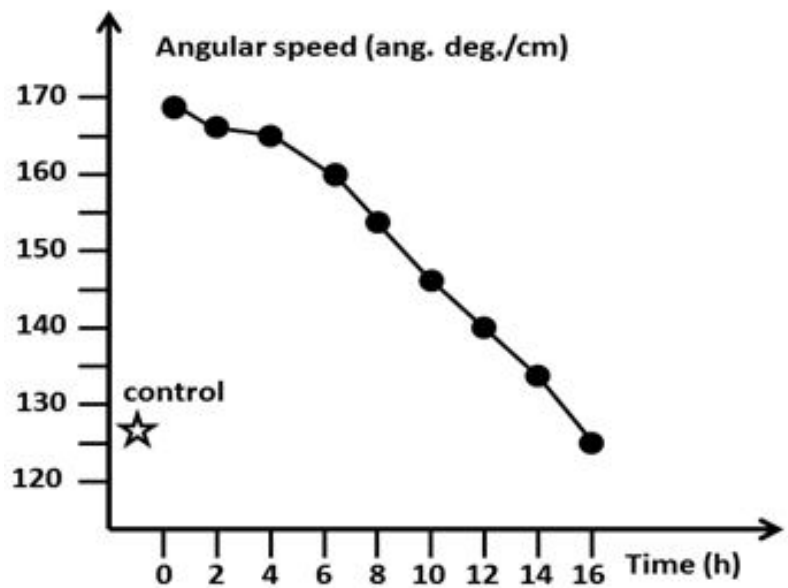

Figure 2: Decrease of the effect of aluminum on the ants' sinuosity after its consumption was stopped. Numerical and statistical results are given in Table 6, details are provided in the text. The effect of aluminum scarcely decreased during 4 hours, then decresed slowly and linearly during 12 more hours, losing $1 / 12$ of its intensity each hour. Such a slow, regular decrease accounted for the absence of addiction to aluminum use

\section{Results}

\section{Meat and Sugar Consumption, General Activity}

These physiological traits were impacted by aluminum consumption (Table 1). Under that diet, the ants eat less meat than when under normal diet (mean number of ants doing so $=0.46$ vs $0.61 ; \mathrm{N}=6, \mathrm{~T}=-21, \mathrm{P}=0.016$ ). On the contrary, they drank somewhat 
more sugar water (mean number of ants doing so $=1.43$ vs 1.04 ), but this result was not significant $(\mathrm{N}=6, \mathrm{~T}=-4,+17, \mathrm{P}=0.109)$. While consuming aluminum, the ants were more active in general, resting less often, than when under normal diet (mean number of active ants $=13.36 v s 10.35)$. This result was significant $(\mathrm{N}=6, \mathrm{~T}=20, \mathrm{P}=0.031)$ and the amount of active ants (consuming aluminum) increased over the six experimental days. A larger activity due to aluminum may explain the slightly larger consumption of sugar water. Such an increase of general activity was very obvious while experimenting, essentially during the late evening (Table 1).

\section{Linear and Angular Speeds}

Aluminum affected the ants' sinuosity of movement but not their speed of locomotion (Table 2, lines 1 and 2). Under that diet, the ants walked at a linear speed nearly similar to that presented while under normal diet (13.7 vs $14.1 \mathrm{~mm} / \mathrm{s})$, the difference between the two speeds of locomotion being not significant $\left(\chi^{2}=1.94, \mathrm{df}=3,0.50<\mathrm{P}<0.70\right)$. While observing the ants, it was obvious that the insects' locomotion under aluminum diet differed from that under normal diet. Numerical results revealed that the difference consisted in an increase of sinuosity (148 vs 126 ang.deg. $/ \mathrm{cm})$, this increase being at the limit of significance $\left(\chi^{2}=7.64, \mathrm{df}=3\right.$, $\mathrm{P}$ 0.05). An increase of sinuosity of movement together with an increase of general activity (see above) was spectacular during some evenings (personal observation). Apparently, this impact of aluminum on the ants' physiology continued days after days, in the course of that metal consumption. An experiment was made after 10 days of consumption for checking this presumption (see below 'Adaptation to aluminum consumption').

\section{Orientation towards an Alarm Signal}

This physiological and ethological trait was affected by aluminum consumption (Table 2, line 3 ). Under normal diet, the ants oriented themselves very well towards a tied worker (38.3 ang. deg.; Figure 1A). When consuming aluminum, these ants did so not so well (59.9 ang. deg.). The difference of orientation capability between ants under one and the other kind of diet was significant $\left(\chi^{2}=16.89, \mathrm{df}=2, \mathrm{P}<0.001\right)$. The large sinuosity of ants consuming aluminum may explain this decrease of orientation capability. However, the ants' olfactory perception (or sensorial perception in general) may also be affected, making thus their orientation towards an alarm signal more difficult. Following experiments examined if aluminum impacted the ants' perception (see below 'Trail following behavior' and 'Tactile (pain) perception').

\section{Trail Following Behavior}

This physiological and ethological trait was impacted by aluminum consumption (Table 2, line 4), what was obvious while experimenting (Figure 1B). Ants living under normal diet followed a circular trail along meanly 12.5 angular arcs of $10^{\circ}$. When consuming aluminum, they followed such a trail along meanly 5.0 angular arcs of $10^{\circ}$. The difference of trail following ability between ants consuming or not aluminum was significant: $\chi^{2}=23.26, \mathrm{df}=2, \mathrm{P}<0.001$. Such a decrease of trail following ability resulted from the ants' increase of sinuosity while consuming aluminum, but may also be due to some decrease of their olfactory perception (or sensorial perception in general). The latter cause was submitted to experimentation in a following experiment (see below 'Tactile (pain) perception').

\section{Audacity}

This trait was slightly affected by aluminum consumption (Table 2, line 5). When living under normal diet, meanly 1.25 ants were seen on the presented unknown apparatus. When consuming aluminum, only 0.90 were meanly seen on that apparatus. This was obvious while experimenting (Figure 1C). Even if running continuously on their foraging area, near their nest entrance as well as inside their nest, the ants consuming aluminum were thus less incline in making risky tasks than while consuming no aluminum. However, the difference of straightforwardness between ants under the two kinds of diet was not significant $(\mathrm{N}=3$, NS) probably due to the smallness of the sample.

\section{Tactile (Pain) Perception}

This physiological trait was impacted by aluminum consumption (Table 2, the two last lines) and this was obvious while experimenting (Figure 1D). Under normal diet, the ants moved very slowly and very sinuously on a rough substrate $(4.7 \mathrm{~mm} / \mathrm{s}$, 257ang.deg./ $\mathrm{cm}$ ). While consuming aluminum, they moved more frankly on such a substrate, just like if they less perceived its uncomfortable character $(8.4 \mathrm{~mm} / \mathrm{s}, 192 \mathrm{ang} . \mathrm{deg} . / \mathrm{cm})$. The difference, between ants under the two kinds of diet, of linear speed as well as of sinuosity on a rough substrate, was significant (linear speed: $\chi^{2}=30.48, \mathrm{df}=2, \mathrm{P}<0.001$; angular speed: $\chi^{2}=23.12, \mathrm{df}=2$, $\mathrm{P}<0.001)$. Aluminum impacted thus the individuals' sensorial perception, a presumption we had on basis of previous experiments (see above 'Orientation towards an alarm signal' and 'Trail following behavior').

\section{Brood Caring}

This trait was not at all impacted by aluminum consumption (Table 3, line 1; Figure 1E). While ants lived under normal diet, 143 ones were counted on the brood in the course of 15 counts, and, among them, 76 ones interacted with the larvae. The mean proportion of ants interacting with the larvae equaled thus 0.53 . While ants consumed aluminum, 158 ones were counted on the 
brood in the course of 15 counts, and among them, 89 interacted with the larvae. The proportion of ants taking care of the brood equaled thus 0.56 . The number of ants present on, as well as of those among them interacting with the brood while ants lived on one hand under normal diet, and on the other hand under aluminum diet did not statistically differ $\left(\chi^{2}=0.04, \mathrm{df}=1,0.80<\mathrm{P}<0.90\right)$. We could thus conclude that, in the absence of any contradictory information, aluminum did not affect the individuals' social relationship, a first conclusion again submitted to experimentation in a following handing (see below 'Aggressiveness against nestmates and aliens').

\section{Cognition}

This trait, reflecting the individuals' physiology and ethology, was impacted by aluminum consumption (Table 3, line 2). Under normal diet, six ants could cross the twists and turns path and reach the area lying beyond, and 10 ones were still moving on the area lying in front of the difficult path, in the course of the 12 experimental minutes. When consuming aluminum, only 4 ants could reach the area lying beyond the twists and turns path, and 16 ones were still in front of it after the 12 experimental minutes. The difference of ants' ability in crossing the twists and turns path between ants under one and the other kind of diet was significant (area in front of the difficult path: $\mathrm{N}=7, \mathrm{~T}=28, \mathrm{P}=0.008$ : area beyond: $\mathrm{N}=5, \mathrm{~T}=+5.5,-9.5, \mathrm{P}=0.359$, the latter result may be due to the smallness of the sample). Since the ants' cognitive abilities (present experiment) and their sensorial perception (three previous experiments, see above) were affected by aluminum consumption, this metal may affect their nervous system in general. A following experiment checked this hypothesis (see below 'Visual and olfactory conditioning and memory').

\section{Aggressiveness against Nestmates and Aliens}

These traits were not at all affected by aluminum consumption (Table 3, lines 3 and 4).

Concerning the aggressiveness against nestmates, ants consuming aluminum behaved as while living under normal diet (Figure $1 F)$. They never gripped or stung their opponent; they contacted them with their antennae, and sometimes, slightly opened their mandibles. The latter act was however a little more often exhibited by ants consuming aluminum (this is why the variable assessing the ants' aggressiveness equaled 0.10 and 0.16 for ants under normal and aluminum diets respectively) but, in fine, the difference of behavior between ants under the two kinds of diet was not significant $\left(\chi^{2}=2.74, \mathrm{df}=2,0.20<\mathrm{P}<0.30\right)$.

As for the ants' aggressiveness against aliens (Figure 1G), it was slightly higher for ants consuming aluminum than for those under normal diet, the variable assessing it equaling respectively 7.08 and 4.50 . In fact, ants under aluminum diet less often contacted their opponent with their antennae, and more often gripped it than ants under normal diet. However, this slight difference (due to the high activity and perhaps the lower perception of ants consuming aluminum) did not make the difference of behavior between ants under one and the other kinds of diet significant $\left(\chi^{2}=3.76, \mathrm{df}=3,0.20<\mathrm{P}<0.30\right)$.

Thus, aluminum did not impact the relationship between members of a colony, as well as that with aliens. This result was in agreement with that concerning the ants' care of brood, another non impacted intra-colonial relationship (see above).

\section{Ability in Escaping From an Enclosure}

This trait was largely impacted by aluminum consumption (Table 3, last line). While under normal diet, ants could escape from the enclosure with some delay. After having been enclosed for 6 minutes, 5 ants among 12 could escape and after 12 minutes, 11 ones could do (Figure $1 \mathrm{H})$. While living under aluminum diet, the ants behaved completely differently. We never saw such a behavior before, even when examining effects of drugs impacting the nervous system $[41,48]$. When under aluminum diet, the enclosed ants walked sinuously all around and also along the rim of the enclosure. However, when being in front of the exit, they went on walking forwards without going out of the enclosure, or looked for a few seconds through the exit, then moved backwards and went on moving inside the enclosure. Among the 12 enclosed ants, no one could escape after 6 minutes, and only 2 could do so after 12 minutes (Figure 1I). The variable assessing the ants' ability in escaping equaled 0.91 for those under normal diet and 0.17 for those under aluminum diet. The difference of escaping ability between ants under one and the other kind of diet was significant $(\mathrm{N}=6, \mathrm{~T}=21, \mathrm{P}=0.016)$. This experimental result showed that aluminum impacted the ants' cognition and straightforwardness, confirming so previous results (see above: 'Audacity' and 'Cognition').

\section{Visual and Olfactory Conditioning and Memory}

These physiological traits were largely impacted by aluminum consumption (Table 4; Figure 1J, K).

Concerning visual conditioning, ants consuming this compound could never acquire any conditioning. After 72 hours of training, they still presented the null score of $50 \%$, while ants living under normal diet reached the excellent score of $80 \%$. This difference was statistically significant $(\mathrm{N}=6, \mathrm{~T}=-21, \mathrm{P}=0.016)$. Aluminum impacted thus the ants' short and probably also middle term visual memory. The ants under aluminum diet having retained nothing of their training, we could not assess the impact of aluminum on their long term memory. We could only state that such ants went on correctly finding their nest entrance and their food sites. Their long term visual memory was thus not, or at least not very largely, impacted by aluminum consumption. 
As for olfactory conditioning, an identical severe impact of aluminum was observed. After 7 hours of training, the ants presented the null score of $50 \%$ while the ants under normal diet had reached the high score of $90 \%$. Such a result was of course statistically significant: $\mathrm{N}=6, \mathrm{~T}=-21, \mathrm{P}=0.016$. Since the ants consuming aluminum acquired no olfactory conditioning, the impact of that compound on their olfactory memory could not be assessed. We could only affirm that aluminum affected the ants' short and middle term memory, and that, probably, it did not, or only slightly, affected the long lasting olfactory memory since the ants went on knowing the odor of their alarm pheromone, trail pheromone, nestmates, brood and queens.

\section{Adaptation to Adverse Effects of Aluminum}

Aluminum impacted the ants' locomotion, increasing their sinuosity of movement (see above and Table 2, line2). After having consumed this metal for 10 days (let us recall that the ants' feeder tubes always contained one or two pieces of aluminum foil), the ants went on moving with a large sinuosity, presenting thus no adaptation to the impact of aluminum on their locomotion. Their sinuosity was even somewhat larger after 10 days than after one day of consumption (Table 5, line 1). This was obvious while experimenting and was confirmed by the numerical results (sinuosity after 10 days of aluminum diet=159 ang.deg./cm) and the statistical analysis (vs normal diet: $\chi^{2}=16.75, \mathrm{df}=3, \mathrm{P}<0.001$; vs after one day of aluminum consumption: $\chi^{2}=9.34, \mathrm{df}=3$, $0.02<\mathrm{P}<0.05)$.

Aluminum impacted the ants' tactile perception (see above and Table 2, last line). After having consumed this compound for 11 days, the ants were still less sensitive to the uncomfortable, painful character of a rough substrate. This was obvious while experimenting, and was confirmed by the obtained numerical (Table 5, line 2) and statistical results. After 11 days of aluminum consumption, the ants' linear speed on a rough substrate was still statistically higher than that presented under normal diet $\left(\chi^{2}=33.29, \mathrm{df}=2, \mathrm{P}<0.001\right)$ and statistically similar to that presented after 5 days of that product consumption $\left(\chi^{2}=4.08, \mathrm{df}=2,0.10<\right.$ $\mathrm{P}<0.20$ ). Similarly, after 11 days of aluminum consumption, the ants' sinuosity on a rough substrate was still statistically lower than that presented under normal diet $\left(\chi^{2}=28.07, \mathrm{df}=2, \mathrm{P}<0.001\right)$ and statistically similar to that presented after 5 days of that product consumption $\left(\chi^{2}=2.6, \mathrm{df}=2,0.20<\mathrm{P}<0.30\right)$.

We can thus definitively conclude that ants did not adapt themselves to the adverse effects of aluminum on their locomotion and tactile perception. Since the effect of aluminum on ants' conditioning and memory was examined after the ants had consumed that compound for 7 days and until they consumed it for 7 more days, and since these ants' traits were found largely impacted by aluminum, we could also conclude that no adaptation occurred as for the impact of aluminum on their nervous system.

\section{Habituation to Effect of Aluminum}

We found no favorable effect of that compound on any examined ants' physiological and ethological traits. We could thus not study habituation.

\section{Dependence of Aluminum Consumption}

Briefly, when experimented after 12 days of aluminum consumption, the ants presented no dependence on that product (Figure 1L). Indeed, when confronted to sugar water containing aluminum and to sugar water free of that metal, 12 ants of colony A as well as 13 ants of colony B were counted on the former liquid while 16 ants of colony A and 13 ants of colony B were counted on the latter liquid. In total, 25 ants preferred the liquid containing aluminum and 20 ones the liquid without this metal. This corresponded to $46.3 \%$ of individuals choosing the food with aluminum and $53.7 \%$ choosing that free of aluminum. The obtained numerical results (25 and 29) did not statistically differ from those (27 and 27) expected if ants randomly went drinking each kind of liquid $\left(\chi^{2}=0.04, \mathrm{df}=1,0.80<\mathrm{P}<0.90\right)$. The ants developed thus no addiction to aluminum consumption, a result related again in the 'Discussion' section.

\section{Decrease of the Effect of Aluminum on the Ants' Sinuosity of Movement after Its Consumption was stopped}

During the first four hours after weaning, the effect of aluminum on the ants' locomotion only very weakly decreased. After that, it slowly and linearly decreased, vanishing in a total of 15 to $16 \mathrm{~h}$ (Table 6, Figure 2). In detail, 8 hours after weaning, the effect of aluminum was not significantly different from that at $\mathrm{t}=0\left(\chi^{2}=0.87, \mathrm{df}=2,0.50<\mathrm{P}<0.70\right)$. Ten hours after weaning, its effect was still no different from that at $\mathrm{t}=0\left(\chi^{2}=2.89, \mathrm{df}=2,0.20<\mathrm{P}<0.30\right)$, though being not different from the control $\left(\chi^{2}=3.65, \mathrm{df}=3, \mathrm{P}=0.30\right)$. Twelve hours after weaning, the effect of aluminum was at the limit of differing from that at $\mathrm{t}=0\left(\chi^{2}=5.79, \mathrm{df}=2,0.05<\mathrm{P}<0.10\right)$, and as for the previous time, not different from the control $\left(\chi^{2}=0.44, \mathrm{df}=2, \mathrm{P}=0.80\right)$. After a total of 14 hours after weaning, the effect of aluminum on the ants' locomotion was again not different from the control one $\left(\chi^{2}=2.00, \mathrm{df}=2,0.30<\mathrm{P}<0.50\right)$, and, unexpectedly not yet different from that at $\mathrm{t}=0\left(\chi^{2}=4.25, \mathrm{df}=2,0.10<\mathrm{P}<0.20\right)$. It was only after 16 hours of weaning that the ants' sinuosity was statistically different from (smaller than) that at $\mathrm{t}=0\left(\chi^{2}=13.31, \mathrm{df}=2, \mathrm{P} \sim 0.001\right)$. The effect of aluminum fully vanished thus in a total of 16 hours after its consumption was stopped (Table 6).

From $4 \mathrm{~h}$ to $16 \mathrm{~h}$ after weaning, the effect of aluminum $\left(\mathrm{E}_{\mathrm{t}}\right)$ decreased over the running time $(\mathrm{t})$, (from its initial value at $\mathrm{t}=0\left(\mathrm{E}_{\mathrm{t} 0}\right)$ until a value identical to the control one) according to the linear function:

$$
\mathrm{E}_{\mathrm{t}}=\mathrm{E}_{\mathrm{t} 0}-3.25 \mathrm{t}
$$


It lost $165-126=39$ ang.deg./ $\mathrm{cm}$ of its full effect in $16 \mathrm{~h}-4 \mathrm{~h}=12 \mathrm{~h}$, and thus $39 / 12=3.25$ every hour. This hourly rate represented $3.25 / 39=1 / 12$ of the total effect. Thus, four hours after the consumption of aluminum was stopped, its effect decreased of $1 / 12$ each hour, what was a slight (slow) decrease, probably not perceived by the individuals, and this accounted for the absence of dependence to aluminum [Cammaerts, accepted by the Journal 'Frontiers in Physiology']. During the first four hours after weaning, the effect of aluminum nearly did not decrease. Consequently, after weaning, aluminum lost its effect in 12 hours following a 4 hours period with no significant decrease.

\section{Discussion}

Using ants as models, we found that sugar water containing pieces of Al foil affected the ants' locomotion, ability in orientating and following a trail, audacity, tactile perception, cognition, ability in escaping from an enclosure, learning, and memory. We now compare our results with those of other researchers on the subject.

Rats receiving, during 6 months, water containing Al dissolved as a salt (Al chloride) showed elevated anxiety: they presented higher ambulatory, rearing activity and defecation index. Their memorization during spatial learning was lower than that of untreated rats, what revealed some cognitive deficit associated with aluminium administration [10]. When routinely orally consumed by rats at human-relevant levels, Al chloride has also been found to impair memory in aging individuals, this cognitive decline being positively correlated with the $\mathrm{Al}$ ingested dose. The cognitive score of these middle and old aged rats was inversely correlated with the percentage of Al loaded in brain entorhinal cortex cells [55]. A following experiment on Al-feed rats showed that increasingly more Al-rich microtubule-depleted pyramidal cells became incorporated in hippocampus lesions when Al gradually accumulated in corticolimbic brain regions, a situation possibly leading to dementia [56]. In these experiments, as in the present study in which we showed that ants' locomotion and memory were affected, Al was present in the water given to the animals. This confers to AL a more than ten times greater bioavailability than when present in solid food [4].

A possible association between $\mathrm{Al}$ in drinking water and the risk of Alzheimer's disease was shown in 9 among 15 former epidemiological studies on human populations [4] and an evident link between ingested Al and this disease was provided by Tomljenovic [3].

Another form of aluminum, Al hydroxyde, a compound poorly soluble in water, but injected as a vaccine adjuvant, has nevertheless been found to be neurotoxic. In contrast to control mice injected with a saline physiological serum, those injected with Al hydroxyde suffered from apoptosis of motor neurons and from motor function impairments (such as a lower linear speed and a higher sinuosity) as well as from spatial learning and memory decreases [57]. The present study also showed that ants fed with sugar water containing pieces of Al foil walked with a higher sinuosity, were less able to orient themselves and to follow a trail. They also presented a large deficit of cognition, learning ability and memory. Moreover, they had their audacity and pain perception reduced. Thus, ants clearly revealed the effects of $\mathrm{Al}$ on the nervous system and muscular systems, and our results converged with those of Shaw \& Petrick [57]. An epidemiological study indicates a correlation between the presence of Al in injected vaccines and the occurrence of autism spectrum disorders [8], revealing once more an impact of Al on the brain functioning. Note that our study on ants, as well as numerous ones of other researchers, never found any impact of $\mathrm{Al}$ on social relationship.

A theory explaining how Al finally injures the central nervous system has been proposed by Shaw and co-authors [58]. Al may disrupt the water-based cellular homeostasis and so cause a cascade of events which begins with inflammatory reactions leading to autoimmune actions impairments and ends by injuring the central nervous system. Indeed, there is a growing evidence that $\mathrm{Al}$ ingested through drinking water promotes the rate of brain aging caused by heightened inflammatory activity within brain tissue $[7,59]$. Furthermore, an histochemical and immunocytochemical research [60] suggests that enhancement of inflammation and pathological changes of cholinergic fibres may be the modes of action through which Al may cause learning and memory deficits.

We observed no adaptation to the adverse effects of Al foil, on the contrary: these effects seemed to increase in the course of the metal consumption. We observed no addiction to aluminum, and this was in accordance with a slow decrease of its effect after its consumption was stopped. Since there is no addiction to aluminum for ants, it is highly probable that there is also no addiction for humans (e.g., they do not try having aluminum in their food, drink or cosmetic). It should thus be easy for humans to live without the presence of aluminum in the numerous products they used, and consequently to find palliatives. Unfortunately, for economical reasons, most people cannot stop using aluminum cookware. However, Al migration can be decreased by a factor up to 60 thanks to a preliminary immersion of the utensils in a more than $90^{\circ}$ water during 5 hours, a process modifying the passivation layer of the foil by forming a low porosity AlOOH interface [61]. This protection against leaching still exists at higher temperature. Anyway, we recommend the advice of Bassioni et al. [28] to not use Al foil for cooking.

A supplementary point must be related. Due to man-made activities including the acidification of rainwater and freshwater and of that of soils by intensive farming, the inert aluminosilicates of the earth crust are now increasingly transformed into aluminum hydroxide and organoaluminum complexes, enhancing in this way our exposure to aluminum. This metal moreover reacts with phosphates which become then less bio available [2]. For environmental reasons also, it is thus recommended to reduce our use of aluminum. 


\section{Conclusion}

Using ants as models, we examined the effects of aluminum foil commonly used by humans. We found that sugar water containing aluminum foil affected the ants' locomotion, ability in orientating and following a trail, audacity, tactile perception, cognition, ability in escaping from an enclosure, learning, memory, but not their social relationship. It leads to no adaptation and no addiction. The effects of aluminum foil vanished slowly in 15-16 hours. Our results confirmed what is related in studies on the effects of aluminum on mammals: it impacts the nervous system, memory, curiosity, coordination of movement, locomotion. Our study gave precision on these effects, and brought new information on the subject, i.e., aluminum decreases meat consumption, impacts the sensitive perception as well as the straightforwardness; no adaptation occurs to the adverse effects (on the contrary) which disappear in about 15 hours after weaning. Aluminum should thus be far less used by humans, the more so because it nowadays pollutes the environment and affects the living organisms' health.

\section{References}

1. Williams RJP (1996) Aluminium and biological systems: an introduction. Coordination Chem Reviews 149: 1-9.

2. Exley C (2003) A biogeochemical cycle for aluminium? J Inorg Biochem 97: 1-7.

3. Tomljenovic L (2011) Aluminum and Alzheimer's disease: after a century of controversy, is there a plausible link? J Alzheimer's Disease 23: 567-98.

4. Krewski D, Yokel RA, Nieboer E, Borchelt D, Cohen J, et al. (2007) Human health risk assessment for aluminum, aluminum oxide, and aluminum hydroxide. J Toxicol Environ health B Crit Rev 10: 1-269.

5. Exley C (2016) The toxicity of aluminium in humans. Morphologie 100: 51-5.

6. Bondy SC (2014) Prolonged exposure to low levels of aluminum leads to changes associated with brain aging and neurodegeneration. Toxicology 315: 1-7.

7. Bondy SC (2016) Low levels of aluminum can lead to behavioral and morphological changes associated with Alzheiner's disease and age-related neurodegeneration. Neurotoxicology 52: 222-9.

8. Tomljenovic L, Shaw CA (2011) Do aluminum vaccine adjuvants contribute to the rising prevalence of autism? J Inorg Biochem 105: $1489-99$.

9. Shaw CA, Tomljenovic L (2013) Aluminum in the central nervous system (CNS): toxicity in humans and animals, vaccine adjuvants and autoimmunity. Immunol Res 56: 304-16.

10. Sethi P, Jyoti A, Singh R, Hussain E, Sharma D (2008) Aluminium-induced electrophysiological, biochemical and cognitive modifications in the hippocampus of aging rats. Neurotoxicology 29: 1069-79.

11. Batisse E (2014) L’aluminium, un produit dangeureux pour la santé present en thérapeutique et en cosmétique: mythe ou réalité. University of Lorraine, France.

12. RASR (2009) Aluminium in food. Risk Assessments Studies Report N ${ }^{\circ} 35$. Centre for Food Safety of the Food and Environmental Hygiene Department, China.

13. Muncke J (2015) Chemical migration from food packaging to food. Reference Module Food Sci.

14. Vela MM, Toma RB, Reiboldt W, Pierri A (1998) Detection of aluminum residue in fresh and stored canned beer. Food Chemistry 63: 235-9.

15. Šeruga M, Grgić J, Mandić M (1994) Aluminium content of soft drinks from aluminum cans. Z Lebensm Unters Forsch 198: 313-6.

16. Verissimo MIS, Teresa M, Gomes SR (2008) Aluminium migration into beverages: are dented cans safe? Sci Total Environm 405: 385-8.

17. Semwal AD, Padmashree A, Khan MA, Sharma GK, Bawa AS (2006) Leaching of aluminium from utensils during cooking of food. J Sci Food Agric 86: 242530.

18 Mohammad FS, Al Zubaidy EAH, Bassioni G (2011) Effect of Aluminum Leaching Process of Cooking Wares on Food. Int J Electrochem Sci 6: $222-30$.

19. Al Zubaidy EAH, Mohammad FS, Bassioni G (2011) Effect of pH, Salinity and Temperature on Aluminum Cookware Leaching During Food Preparation. Int J Electrochem Sci 6: 6424-41.

20. Greger JL, Goetz W, Sullivan D (1985) Aluminum levels in foods cooked and stored in aluminum pans, trays and foil. J Food Protection 48: $772-7$.

21. Brunner B, Arnold R, Stolle A (1999) Uebergang von aluminium auf lebensmittel. Verwendung von folien bei kuechentechnischer zubereitung von fisch und fleisch. Fleischwirtschaft 99: 110-2.

22. Ranau R, Oehlenschläger J, Steinhart H (2001) Aluminium levels of fish fillets baked and grilled in aluminium foil. Food Chemistry 73: 1-6.

23. Turhan S (2006) Aluminium contents in baked meats wrapped in aluminium foil. Meat Science 74: 644-7.

24. WHO (1989) World Health Organization Technical Report Series, Geneva, Switzerland.

25. Takeda Y, Kawamura Y, Yamada (1998) Dissolution of aluminium from aluminium foil products in food-simulating solvents. J Food Hygienic Soc Japan 39: $178-83$.

26. Takeda Y, Kawamura Y, Yamada (1998) Dissolution of aluminium from aluminium into foods and effect of food components on the dissolution. J Food Hygienic Soc Japan 39: 266-71.

27. Ekanem EJ, Lori JA, Okibe FG, Shallangwa GA, Anhwange BA, et al. (2009) Determination of Aluminium in Different Sources and its Contribution to Daily Dietary Intake in Nigeria. J Appl Sci Res. 5: 944-8.

28 Bassioni G, Mohammad FS, Al Zubaidy E, Kobrsi I (2012) Risk Assessment of Using Aluminum Foil in Food Preparation. Int J Electrochem Sci 7: 4498-509. 29 WHO (2008) Commission du Codex alimentarius, Geneva, Switzerland.

30. EFSA (2008) Safety of aluminium from dietary intake. EFSA J 754: 1-34.

31. Fekete V, Vandevijvere S, Bolle F, Van Loco J (2013) Estimation of dietary aluminum exposure of the Belgian adult population: evaluation of contribution of food and kitchenware. Food Chem Toxicol 55: 602-8.

32.Wehner R, Gehring W (1999) Biologie et Physiologie Animales; De Boek Université, Thieme Verlag: Paris, Bruxelles,Belgium.

33.Sherwood L, Klandorf H, Yancey P (2016) Physiologie animale. Rue du Bosquet, Louvain-la-Neuve, Belgium.

34. Bousquet C (2003) Bêtes de science. Seuil, 240 pp. 
35. Wolf FW, Heberlein U (2003) Invertebrate models of drug abuse. J Neurobiol 54: 161-78.

36. Andre RG, Wirtz RA, Das YT (1989) Insect Models for Biomedical Research. In: Non mammalian Animal Models for Biomedical Research. Boca Raton, CRC Press, FL, USA.

37 Keller RA (2011) A phylogenetic analysis of ant morphology (Hymenoptera: Formicidae) with special reference to the Poneromorph subfamilies. Bull Am Museum Nat Hist 355: 1-90.

38. Billen J, Morgan ED (1998) Pheromone communication in social insects - sources and secretions. In: Pheromone Communication in Social Insects: Ants, Wasps, Bees, and Termites. Westview Press: Boulder, Colorado.

39. Passera L, Aron S (2005) Les fourmis: comportement, organisation sociale et évolution; Les Presses Scientifiques du CNRC: Ottawa Canada.

40. Hölldobler B, Wilson EO (1990) The ants. Harvard University Press, Springer-Verlag: Berlin, Germany.

41. Cammaerts MC (2016) Ants as biological models for studying effects of substances used by humans. JSM Anat Physiol 1: 1003.

42. Cammaerts MC, Cammaerts D (2014) Comparative outlook over three Myrmica species' biotopes and foragers' know-how. Biologia 69: 1051-8.

43.Cammaerts MC, Cammaerts R (2015) Acquisition of ants' cognitive abilities (Hymenoptera, Formicidae). Advanced Studies Biology 7: $335-48$.

44. Cammaerts MC, De Doncker P, Patris X, Bellens F, Rachidi Z, Cammaerts D (2012) GSM 900 MHz radiations inhibits ants' association between food sites and encountered cues. Electrom Biol Med 31: 151-65.

45. Cammaerts MC, Rachidi Z, Bellens F, De Doncker P (2013) Food collection and responses to pheromones in an ant species exposed to electromagnetic radiation. Electrom Biol Med 33: 315-32.

46. Cammaerts MC, Cammaerts R (2016) Ethological and physiological effects of paroxetine, the nowadays most consumed antidepressant: A study on ants as models. Res Trend 12: 107-26.

47. Cammaerts MC, Cammaerts D (2015) Potential harmful effects of carbamazepine on aquatic organisms, a study using ants as invertebrate models. Int J Biol 7: 75- 93.

48. Cammaerts MC (2017) Some findings on ants as models, which should be considered for caring of humans. MOJ Biology and Medicine 1: 00027.

49. Cammaerts MC (2017) Biological effects of curcuma, a potential safe analgesic; a study on ants as models. EC nutrition 11: 99-116.

50. Bruxelles Environnement (2013) Observatoire des données de l'environnement.

51. Siegel S, Castellan NJ (1989) Non-parametric statistics for the behavioural sciences. McGraw-Hill Book Company: Singapore.

52. Cammaerts MC, Morel F, Martino F, Warzée N (2012) An easy and cheap software-based method to assess two-dimensional trajectories parameters. Belg J Zool 142: 145-51.

53. Cammaerts MC, Gosset G, Rachidi Z (2014) Some physiological and ethological effects of nicotine; studies on the ant Myrmica sabuleti as a biological model. Int J Biol 6: 64-81.

54. Cammaerts MC, Cammaerts D (2017) Physiological effects of statins; a study on ants as models. A J Pharmaceut Res Health Care 9: $1250-460$.

55. Walton JR (2009) Functional impairment in aged rats chronically exposed to human range dietary aluminum equivalents. NeuroToxicol 30 : $182-93$.

56. Walton JR (2009) Brain lesions comprised of aluminum-rich cells that lack microtubules may be associated with the cognitive deficit of Alzheimer's disease. NeuroToxicol 30: 1059-69.

57. Shaw CA, Petrik MS (2009) Aluminum hydroxide injections lead to motor deficits and motor degeneration. J Inorg Biochem 103: $1555-62$.

58. Shaw CA, Kette SD, Davidson RM, Seneff S (2013) Aluminum's role in CNS-immune system interactions leading to neurological disorders. Immunome Res 9: $1-16$.

59. Campbell A, Becaria A, Lahiri DK, Sharman K, Bondy SC (2004) Chronic exposure to aluminum in drinking water increases inflammatory parameters selectively in the brain. J Neurosci Res 75: 565-72.

60. Platt B, Fiddler G, Riedel G, Henderson Z (2001) Aluminium toxicity in the rat brain: Histochemical and immunocytochemical evidence. Brain Res Bull 55: 257-67

61. Karbouj R, Desloges I, Nortier P (2009) A simple pre-treatment of aluminium cookware to minimize aluminium transfer to food. Food Chem Toxicol 47: $571-7$.

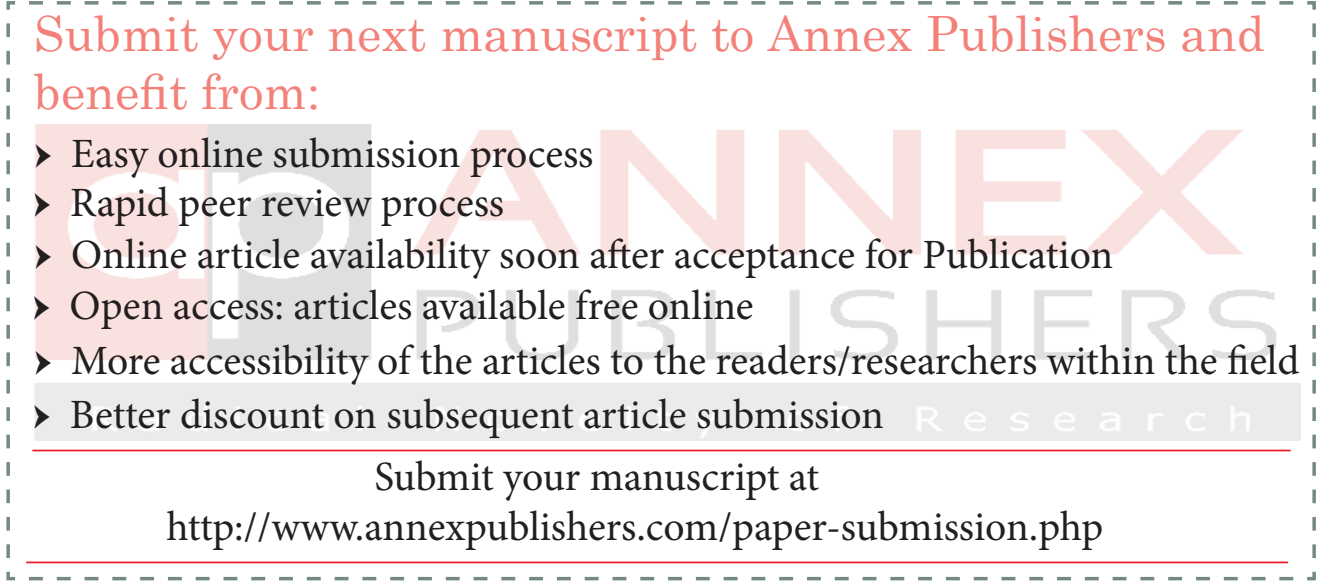

